\title{
Radiation-induced Changes in the Electrophoretic Profile of Serum Albumin
}

\author{
Celso Vieira Lima ${ }^{1 *}$, Tarcisio Passos Ribeiro Campos ${ }^{1}$. \\ ${ }^{1}$ Universidade Federal de Minas Gerais - Ciências e Técnicas Nucleares, Belo Horizonte, Minas Gerais, Brazil.
}

\begin{abstract}
Albumin protein profiles were investigated in electrophoresis system in relation to the whole body exposition to the radiation. Two groups of rats Wistar were set up as the control $(C G)$ and the irradiated one (IG). The IG was exposed to Co-60 at a dose of 5 Gy. After a 72-hour exposition, $300 \mu \mathrm{L}$ of blood was collected in the inferior vena cava, renal, jugular, hepatic, and pulmonary veins and the serum separated. The albumin protein was identified by vertical electrophoresis in acrylamide Commassi blue or silver stained. The calibration procedure was applied to albumin samples with well-known concentrations. The mathematical correlation was developed involving electrophoretic parameters of band intensities and sizes from gel representation, providing values of protein concentrations in comparison with standard bands with known concentrations. There were significant differences in the physiological concentrations in the jugular and pulmonary sites in relation to renal and cava regional sites. Significant differences induced by radiation in serum albumin concentration were also found in hepatic and jugular sites. Alteration of albumin concentration was found as a nearly effect from whole body irradiation. This phenomenon points out to alterations in cell metabolism in the liver justified by a possible indication of proteomics damage from radiation.
\end{abstract}

Key words: serum protein, rats, radiation, albumin, electrophoresis.

\footnotetext{
*Author for correspondence: limacv2004@yahoo.com.br, tprcampos@yahoo.com.br
} 


\section{INTRODUCTION}

Limiting factors on human life, such as aging and cancer, are the theme of research to mitigate or remediate their effects. The basis of cancer control, whether surgically removed or not, remains on radiotherapy and chemotherapy. Radiation induces molecular, cellular, and tissue effects ${ }^{1,2}$. There are no doubts about the effectiveness of radiotherapy, but the quantization and the minimization of the deleterious effects should always be pursued, especially on blood and in normal tissues ${ }^{3,4}$.

Human blood is composed of over 500 different proteins, and approximately 12 of them are of paramount importance for maintaining the metabolic functions of the blood. The main plasmatic proteins are albumin, antitrypsin, TBG, alpha-fetoprotein, alpha1-acid glycoprotein, alpha2-globulin, haptoglobin, macroglobulin, ceruplasmin, immunoglobulin, transferrin, C3, and betalipoprotein. All these proteins are formed by chains of amino acids joined together by peptide bonds, globulins, and immunoglobulins ${ }^{5}$.

The most abundant plasma protein is albumin, representing $60 \%$ of the total protein content, accounting for $80 \%$ of blood oncotic pressure and the transport of substances, such as bilirubin, calcium, hormones, drugs, and also for controlling the plasma $\mathrm{pH}$, among other functions. It is synthesized exclusively in the liver, being released as preproalbumina ${ }^{6}$. After removing the initial sequences, the action of the proalbuminenzymes will be modified by the removal of six residues from the new $\mathrm{N}$ terminus propeptide. Thus, albumin appears shaped and sent to the blood with a halflife of 19 days. Recent studies indicate that serum albumin is approaching an ellipsoid of 140 x 40 Angstroms with three homologous domains of $67 \mathrm{kDa}$ and the human plasma concentration near $5.0 \mathrm{mg} \cdot \mathrm{dL}^{-1}$. Albumin is filtered in the nephrons, being reabsorbed by the distal peritubular capillaries. Albumin can be released in the urine when there is the presence of renal glomeruli damaged ${ }^{5-7}$.

The relative concentration of albumin in serum can be analyzed by electrophoresis. Protein electrophoresis is a very simple technique that uses electrophoresis forces and electro-endosmosis present in the system ${ }^{8}$. The separated fractions are visible after treatment with the proteins sensitive dyes. The present study is to characterize and analyze electrophoresis profiles of the protein albumin in control and irradiated animal model.

This study proposes the investigation of the albumin profiles in vertical electrophoresis system after whole body exposition to Co-60 irradiation at a dose of 5 Gy, collected from serum blood taken in the inferior vena cava, renal, jugular, hepatic, and pulmonary veins in animal model.

\section{MATERIALS AND METHODS}

Grouping and ethical treatment: Two groups of isogenic animals, Wistar rats, were used with 12 weeks old and weighed $300 \pm 10 \mathrm{~g}$, with free access to water and food with a photoperiod of $12 \mathrm{~h}$; holding same feed and ambient conditions. The animals were divided into control groups- CG $(n=6)$ and one subjected to irradiation - IG $(\mathrm{n}=6)$. The same lineage, family, weight, and age were preserved. The Ethical Committee, CEUA - UFMG 339/2014, previously approved the research project.

Irradiation: The animals were exposed together to a dose of 5 Gy of Co-60, Laboratory of Gamma Irradiation - LIG, Centro de Desenvolvimento de Tecnologia Nuclear-CDTN at same irradiation conditions, time and absorbed dose. 
Sample time, collection and separation of components: Blood samples were obtained from IG and CG groups after a 72-hourexposure. Under deep anesthesia, thoracic and abdominal laparotomies were performed, and subsequently, $300 \mu \mathrm{L}$ of blood was collected from the inferior vena cava, renal, jugular, hepatic, and pulmonary veins in heparin tubes. The samples were submitted to centrifugation at $2500 \mathrm{rpm}$ for $30 \mathrm{~min}$ to separate their components.

Electrophoresis: Serum samples from the distinct vascular sites and animal groups were submitted to vertical electrophoresis of acrylamide, SDS-PAGE. The gels were prepared at $10 \%$, with a comb of $4 \%$ gel and run to $120 \mathrm{~V}$ and $15 \mathrm{~mA}$. An amount of $15 \mu \mathrm{L}$ sample was used in the wells. After the run, the gels were stained with Commassi blue R-250or silver and then fixed.

Scanning and processing information: The electrophoresis profile of proteins was digitized in transmission scanner, identified, and analyzed using the digital imaging system Image ${ }^{\circledR}$.

Isogenic test: Blood samples from isogenic animals in the control group, living in a controlled environment, were collected in different periods (times and days) and different vascular sites, being one sample from each animal. Serum samples were separated and electrophoresis was prepared as previously described. Distinct staining standardizations were tested. A set of a pair of bands from a distinct time and a site were compared to check the equivalent protein expression.

Standardization of Albumin: A standard sample with albumin concentration of 4.0 g.dL ${ }^{-1}$ from Bradford assay was employed. Also, a high range protein molecular weight was used. SDS-PAGE was run with framework-eluted concentrations and stained with Commassi Blue R-250. The intensity of the gray level of the image after digitalization and treatment in ImageJ software was obtained and generated the patterns of intensities, band areas, and the concentration level for performing a semianalytical analysis.

Semi-quantitative analysis: Small aliquots of albumin obtained from diluted patterns were quantified by Bradford assay. In the gel, a scale of the level of intensities and areas of the bands were created related to the measured concentration. The electrophoresis and stain conditions were preserved. The relative intensities and areas of the bands from the gels provided a relationship to the standard concentrations, holding a mathematical correlation. The following equation was proposed:

$C . D=\left(C_{p} \cdot D_{p}\right) \cdot\left\{(V \cdot P) /\left(V_{p} \cdot P_{p}\right)\right\} \cdot\left\{\left(I^{b} \cdot A^{b}\right) /\left(A^{b}{ }_{p} I_{p}^{b}\right)\right\}^{n}$,

in which: $C$ and $C_{p}$ are the protein concentrations in $\mathrm{g} \cdot \mathrm{dL}^{-1}$ of the sample and of the standard; $D$ and $D_{p}$ are the dilution fraction of the sample and the standard; $V$ and $V_{p}$ are the volumes of the sample and the standard applied in the lanes of the electrophoresis, in $\mu \mathrm{L} ; P_{p}$ and $P$, protein abundances on the whole medium applied, in percentage (\%), from the sample and the standard; $A^{b}$ and $A_{p}^{b}$, protein band areas of the sample and the standard, in $\mathrm{mm}^{2}$; and, $I^{b}$ and $I_{p}^{b}$, protein band intensity of the sample and the standard, in gray level intensity, and $n$ is an arbitrary number adjusted by calibration. The use of such method is justified due to the small amount of serum removed in each vascular site. 
Statistical analysis: Electrophoresis of three samples from the isogenic animal control group was prepared following the same methodological conditions and electrophoretic parameters. The standard deviations in the gray level intensity and an area from the albumin bands were evaluated, and its maximum deviation was applied to perform statistical analysis in all irradiation samples.

\section{RESULTS}

Standardization of Albumin in electrophoresis and standard deviation analysis.Fig.1 illustrates the response of the experiment to standardize the albumin protein in SDSPAGE under operation conditions. After imaging, one can observe the changes in patterns of the area and the gray level intensities of the bands in relation to the albumin concentrations and dilution. The gray level intensities in the distinct protein bands, normalized in percentage, were $68.78,28.72,5.00$ and $1.45 \%$. It was found at pre-established concentrations of $4.0 \mathrm{~g} . \mathrm{dL}^{-1}$ com dilution of $1: 1,1: 2,1: 5,1: 10$, providing a diluted concentration of $4.0,2.0,0.8,0.4 \mathrm{~g} . \mathrm{dL}^{-1}$, respectively.

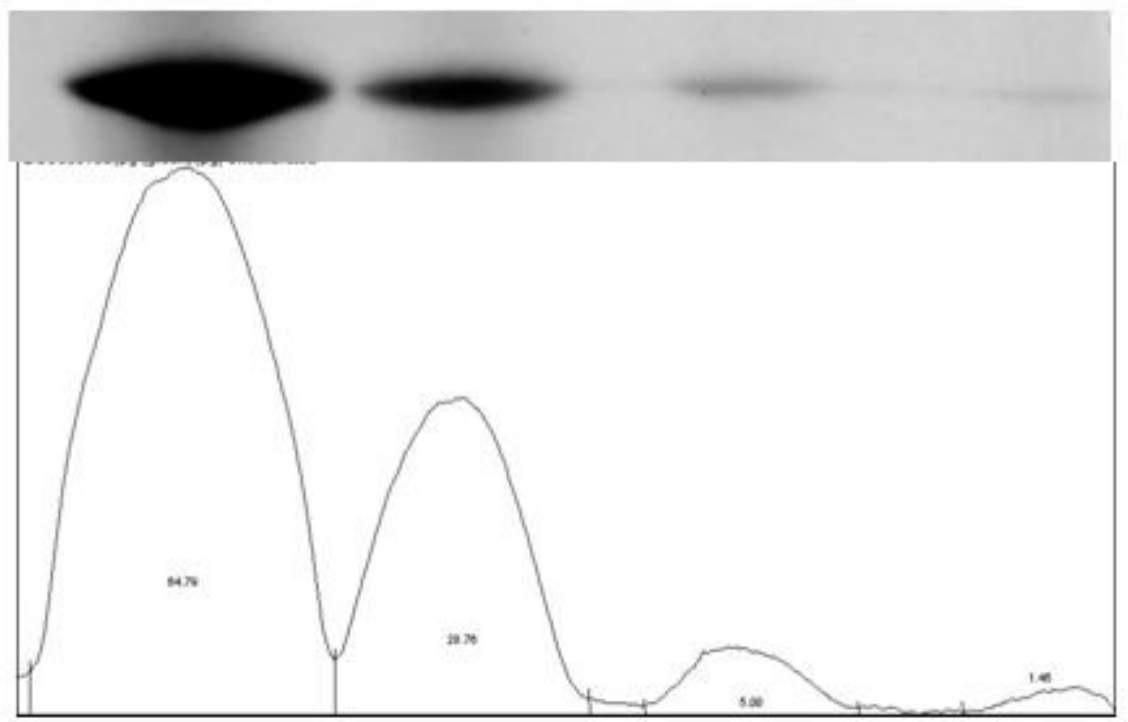

Figure 1 - Standardization of albumin concentrations in SDS-PAGE gel and Commassi blue stained.

Based on the calibration process of the albumin, the parameter $n$ was found equal to 0.60. Therefore Eq.1 could provide an estimate of the concentrations on each lane taken one band as a reference " $p$ ". As described on Eq.1, the unknown concentration $C$ will depend on the parameters of application $C_{p}, D_{p}, V_{p}, P_{p}$ and the ratio of the product of the area $A_{p}$ and intensity $I_{p}$ from gel images for the standard protein denoted $p$, taken as a reference, and the lane whose concentration shall be estimated. If applying data from Fig.1 in Eq.1, one can verify the concentration $C$ of the albumin in each albumin band on its lane, considering one of them as standard $p$ with $C_{p}, D_{p}, V_{p}$ and $P_{p}$ known. Thus, let us consider the data from lane 1 being known $\left(C_{p}=4.0 ; D_{p}=1: 1\right)$, based on the data from the image of lane 2, 3 and 4 , with dilution $D$ of 1:2, 1:5 and 1:10. From Eq.1, one can estimate the real concentration applied with an error of $13 \%$ (lane 2), 1\% (lane 3), and -5\% (lane 4), only based on the representation of the band area and intensity on Commassi blue stained. Taken now lane 4 as standard $\left(C_{p}=0.4, D_{p}=1: 10\right)$, the concentration on lane 3 can be estimated, in relation to 4 , with an error of $-6 \%$. The same between lanes 2 to 3 estimated with a concentration error of $-12 \%$. The larger error was found when lane 1 was taken as reference. Maybe, it is due to the large amount of protein running on the 
electrophoresis that did not stain completely on the gel properly, losing a small part of it; in turn, for a small amount of protein (lane 4) error is large. Such results from the standard albumin band validate the proposed expression (Eq. 1) for estimating concentration in gel electrophoresis taken a known standard band $p$; assuming an overestimation behavior of $+13 \%$ at the interval of $1.0-4.0 \mathrm{~g} \cdot \mathrm{dL}^{-1}$, and an underestimation behavior of $-12 \%$ at the concentration lower than $1.0 \mathrm{~g} . \mathrm{dL}^{-1}$.

Based on the analysis of the Commassi blue stained electrophoresis gel of the samples from the CG group, the deviation found from the estimate of the value $A_{p} I_{p}$ was $\pm 8.1 \%$. Such deviation was applied to all gel analysis.

Isogenic test in CG group: Fig. 2 presents the silver stained electrophoresis gels from samples taken at isogenic Wister rats from systemic, jugular and cava sites. The comparison was made in a distinct pair of times from distinct animals living in a controlled environment. The samples from inferior vein cava (systemic): (12h, 2d), (3d,4d), (7d,2d); and, jugular vein: (7d,1d), (7d,30d)were compared.

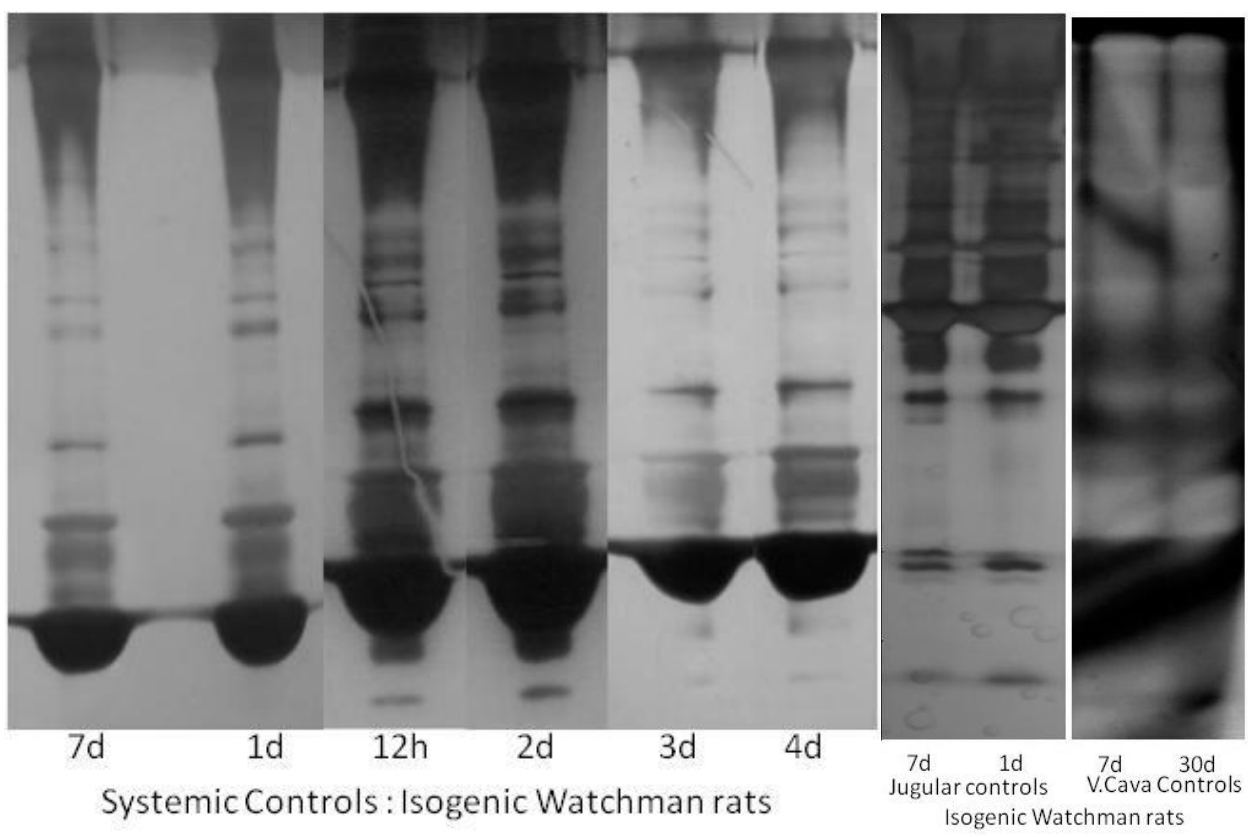

Figure 2 - The silver stained electrophoresis gels from samples taken at isogenic Wistar rats taken from systemic, jugular and cava vein sites, compared at distinct periods of days, in silver stained.

Analysis at the albumin concentration in control group gel in distinct vascular sites: Fig 3 presents examples of a digitalized silver stained electrophoresis image followed by intensity profiles from albumin cut band, prepared with $15 \mu \mathrm{L}$ plasma samples from regional jugular, renal, hepatic, vena cava and pulmonary veins of the CG group. 


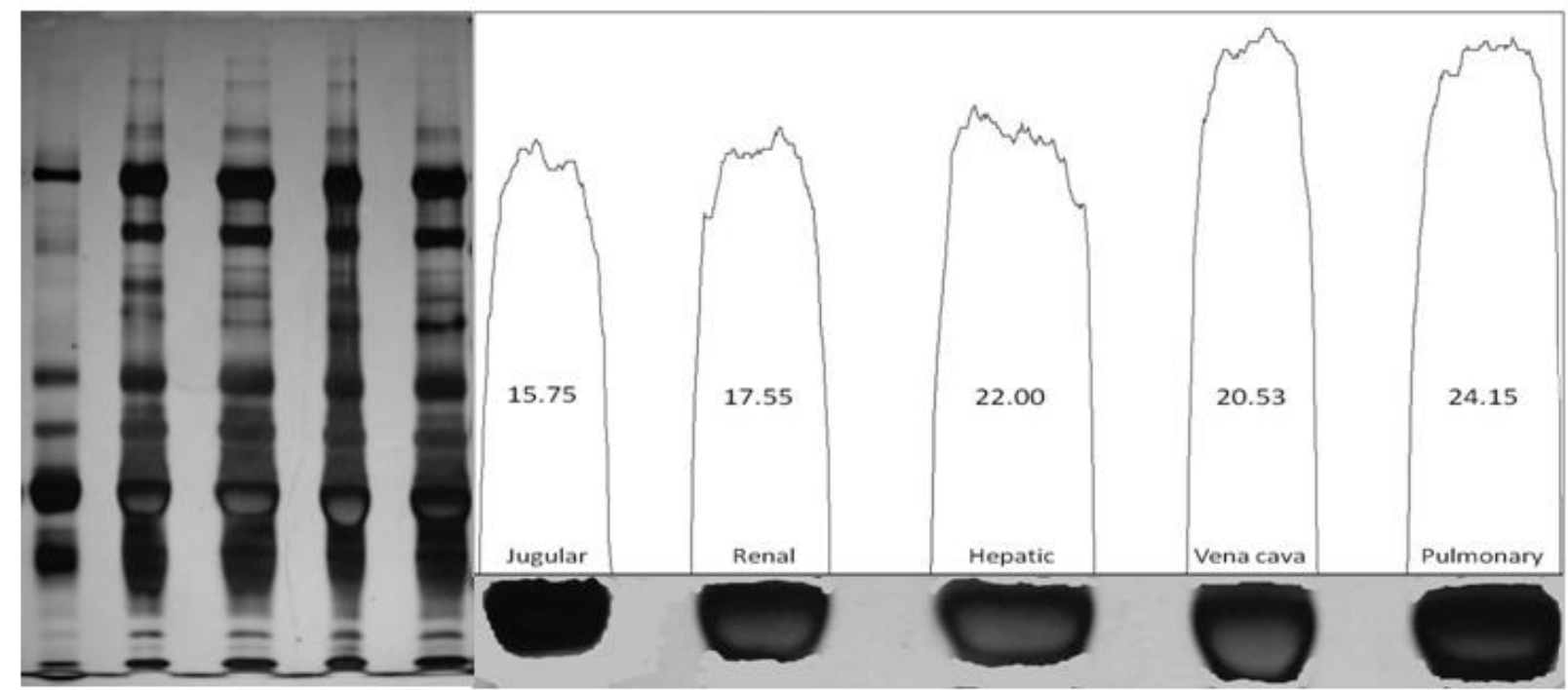

Figure 3-Digitalized silver staining electrophoresis image and intensity profiles from albumin cut band prepared with $15 \mu \mathrm{L}$ plasma samples from jugular, renal, hepatic, vena cava and pulmonary veins.

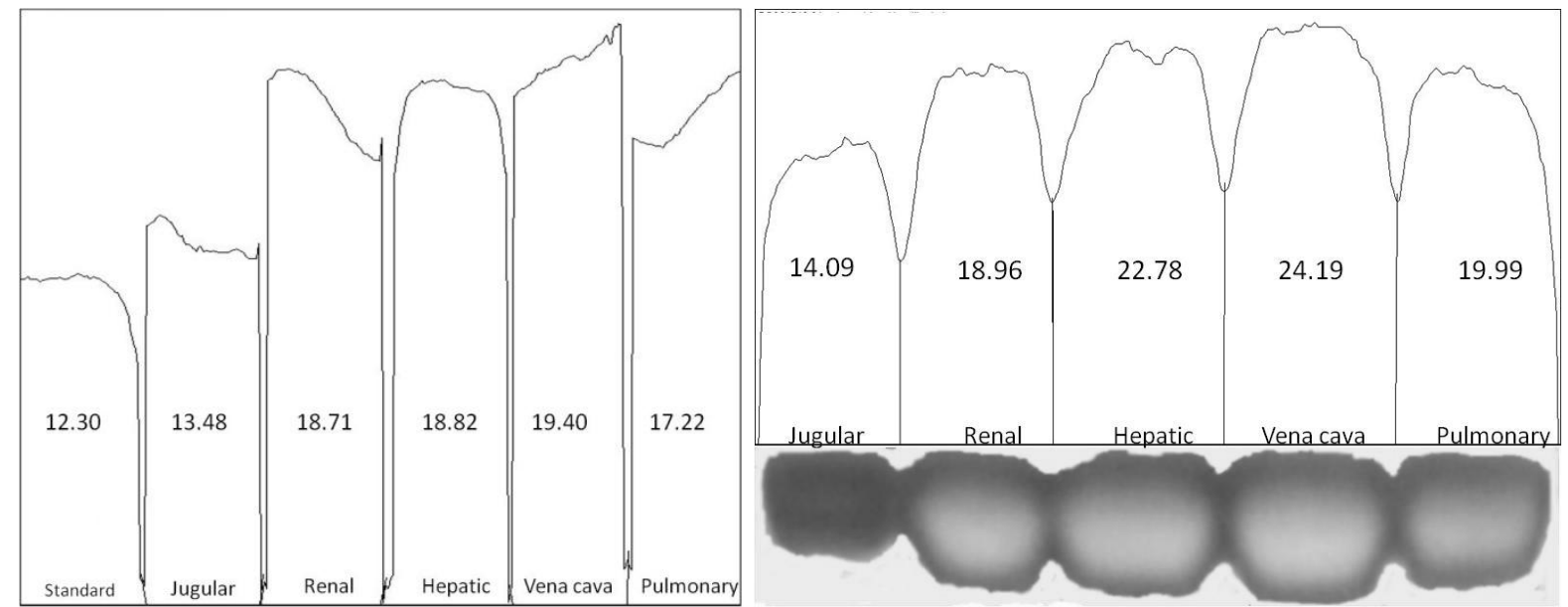

Figure 4- Intensity variation profiles from ImageJ analysis at (a) blue stained electrophoresis image for standard diluted albumin at $10 \mu \mathrm{L}$ with $0.4 \mathrm{~g} . \mathrm{dL}^{-1}$; and, $15 \mu \mathrm{L}$ plasma samples, and at (b) silver stained electrophoresis image, obtained from the jugular, renal, hepatic, vena cava and pulmonary veins.

An example of a Commassi stained gel profile of the CG group in which the albumin bands were recorded and identified is shown in Fig. 4.According to the maximum standard deviation of $\pm 8.1 \%$ observed on the overall control group, there is no statistic difference between renal, hepatic and vena cava samples; however, differences in jugular and pulmonary sites were found in CG samples, and pulmonary samples presented large standard deviation. In the overall samples, the average and standard deviation of the albumin concentration at jugular, renal, hepatic, vena cava and pulmonary veins were $15.1 \pm 0.7 \%, 19.3 \pm 1.4 \%, 22.1 \pm 0.5 \%$, $22.3 \pm 1.3 \%, 21.3 \pm 1.9 \%$, respectively.

As the blood was treated with heparin, pure heparin was assessed by SDS-PAGE verifying the absence of bands in the range of interest following the conditions of the experiments. Thus, it was shown that heparin does not interfere with the electrophoresis data.

Applying Eq.1 in the blue stained samples running with analbumin standard, one can find the concentration of such protein based on band profile. Tab. 1 shows as an example the regional variation of albumin concentrations in the vascular sites, 
pointing out that these changes are related to the animal physiological control. The band intensities of physiological albumin serum in the CG group, taken in vascular sites of jugular, renal, hepatic, inferior vena cava and pulmonary veins, respectively, showed $9.5 \%, 52.1 \%, 52.9 \%$ and $58.1 \%$, and $40.0 \%$ higher than the standard albumin concentration recorded by electrophoresis. Values were adjusted by the diverse concentrations of applied samples, areas, and intensities found in the stained bands. Concentration was achieved through Eq.1. In the stained gels, Tab. 1 depicts significant difference in the physiological concentrations in jugular and pulmonary sites in relation to renal, hepatic and cava sites.

Table 1 - Concentrations in control group, in g. $\mathrm{dL}^{-1}$, and relative percentage changes normalized in relation to standard albumin value.

\begin{tabular}{llll}
\hline Venous vascular site & $\begin{array}{l}\text { Intensity } \\
\text { Relative } \\
\text { standard }\end{array}$ & $\begin{array}{c}\mathrm{C} \\
\text { to }\left[\mathrm{g} . \mathrm{dL}^{-1}\right]\end{array}$ & $\begin{array}{c}\text { Standard } \\
\text { deviation }\end{array}$ \\
\hline Jugular & 1.09 & $* 2.62$ & 0.21 \\
Renal & 1.52 & 4.60 & 0.37 \\
Hepatic & 1.52 & 3.61 & 0.29 \\
Cava & 1.58 & 4.39 & 0.36 \\
Pulmonary & 1.40 & $* 2.45$ & 0.20 \\
\hline
\end{tabular}

Analysis at the irradiated group: A decrease in the color intensity of the band stains was observed in electrophoresis albumin bands in almost all sites surveyed from the irradiated group, with the exception of the renal site. This analysis was made comparing to albumin bands from CG group and the IG one, shown in Fig.5. Also, Fig. 6 depicts the pulmonary and jugular lanes of electrophoresis profiles from CG and IG groups, as an example, demonstrating the lower area and intensity in albumin band at the gel, which represents a lower concentration found after radiation.

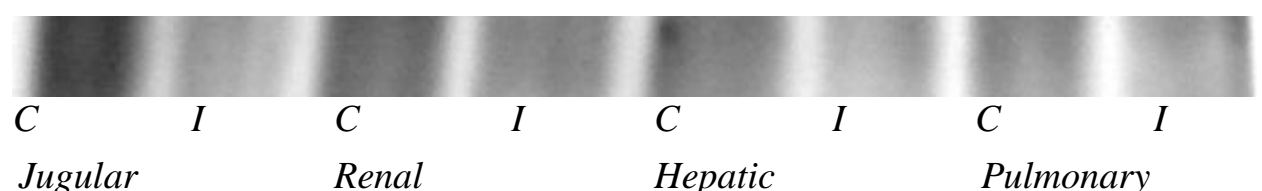

Figure 5 - Serum albumin bands at SDS-PAGE from samples at vascular sites: jugular, renal, hepatic, pulmonary veins from control $(C)$ and irradiated $(I)$ groups, respectively.

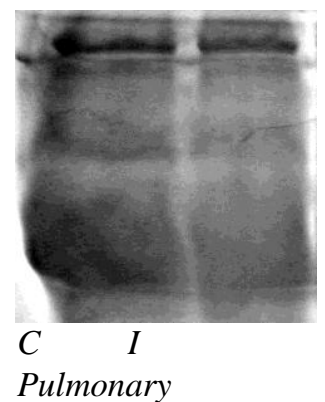

(a)

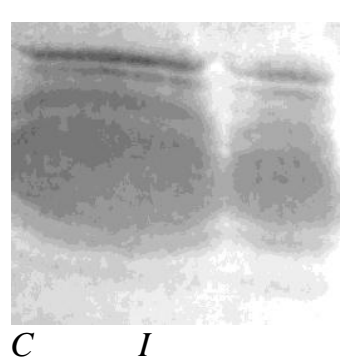

Jugular

(b)

Figure 6 - SDS-PAGE from samples of a) the control and the irradiated pulmonary vein, b) the control $(C)$ and the irradiated $(I)$ jugular veins. 
Table 2 - Protein concentration and the normalized values in the investigated sites.

\begin{tabular}{llll}
\hline Vascular site & \multicolumn{2}{l}{$\begin{array}{l}\text { Concentration } \\
\text { groups [g.dL-1] }\end{array}$} & $\begin{array}{c}\text { in } \\
\text { [geduction } \\
\end{array}$ \\
\cline { 2 - 3 } & Control & Irradiated & \\
\hline Jugular & 2.62 & 2.00 & $* 23.8$ \\
Renal & 4.60 & 4.45 & 3.0 \\
Hepatic & 3.61 & 3.05 & $* 16.1$ \\
Pulmonary & 2.45 & 2.29 & 6.2 \\
\hline
\end{tabular}

* Statistically different for jugular and hepatic.

Table 2 summarizes the results, in which the quantitative values representing the albumin concentration reduction are presented in the vascular sites under study. There were significant reductions in the albumin concentration in jugular and hepatic sites in relation to control. The concentrations estimated by Eq.1, especially the irradiation group, were found in the interval of 1.0-4.0 g.dL $\mathrm{dL}^{-1}$ so that those observed in the calibration process may be overestimated in the range of 5 to $13 \%$. Therefore the effect of reduction of the concentration may be a little larger than presented.

\section{DISCUSSION}

The study of blood proteins particularly albumin in their biochemical aspects, such as molecular weight, the structure of the spatial chain and its concentration in blood, starts in the 1960s ${ }^{9}$.As an example, Deim K. (1962) had studied a profile of blood proteins assigning their functions and physic-chemical features ${ }^{9}$. In previous studies, there was no concern of changes on plasma protein concentrations induced by extrinsic phenomena such as radiation and its consequences on the human metabuloma.

Later in 1976, Anderson and Warner showed the effects of ionizing radiation in producing several blood alterations in the exposed human body, confirming the findings in victims of nuclear weapons in Hiroshima and Nagasaki ${ }^{10}$. They addressed that the immune suppression is the most important blood deleterious effect. Such blood alterations have been casually demonstrated in exposed subjects in various nuclear events, such as the Goiania accident in Brazil, Chernobyl in 1991, and recently Fukushima in $2011^{11}$.

Recently, proteomic analysis from radiation exposure subjects has been addressed ${ }^{12}$. Tapio et al., 2013, described a series of changes for different blood proteins, as SILAC, which is very sensitive to radiation, due to inhibition of its synthesis ${ }^{13}$.By contrast, Nylund et al., 2013, reported no changes in the protein expressions of the endothelial cell line (EA.hy926) submitted to radiation ${ }^{13,14}$.Yan et al., 2010, described the metabolism increase of skin fibroblasts and concluded that such behavior is due to resistance mechanisms of radiation cells ${ }^{15}$.Further studies, Yuasa et al., 2006, showed that the changes in protein expressions shall start with the interactions of radiation in the process of DNA replication, which can be occasional or permanent, and this gene reprogramming transmitted to new populations or new cell generations ${ }^{16}$. In additional studies, involving electromagnetic radiation such as cell phone signal or computer, Karinem et al., 2008, based on a female volunteer group, showed small changes in skin protein expressions although not conclusive ${ }^{17}$. In addition, Fragopoulou et al., 2012, demonstrated through 2D-PAGE electrophoresis, changes in the expression and function of 100 proteins in blood ${ }^{18}$. On many of those 1D and 2D electrophoresis studies, special kits previously remove immunoglobulins and albumin proteins, since its band covers large space of the gel and it is stained easily, creating difficulty in separating small spots of low expression proteins. 
Moreover, Mattos et al., 2002, performed protein activation studies, specifically on transforming growth factor - TGF in lung from in vivo irradiated mice ${ }^{19}$. They demonstrated the existence of two isoforms of TGF $\beta 1$ cytokines, being latent and another active. The inactive form is linked to a latency-associated peptide - LAP, which is degraded by plasmin that is an enzyme involved in this process. In normal animals, there are constant proportions of latent and active TGF $\beta 1$, which determines the thickness of the lung parenchyma and its normal physiology with no collagen deposition. However, after the whole body animal irradiation with 7 Gy in Co-60, there is a reduction of the latent TGF $\beta 1$ with the increase of active TGF $\beta 1$; having, as a consequence, collagen deposition and lung's parenchyma thickness increase. It is a more evident phenomenon at 14 and 30 days after irradiation. This effect was confirmed by immune histochemical studies, showing the reprogramming of gene expression. Falcão et al. also found TGF and MMP9 metalloproteinase alterations in skin induced by UV radiation, which may be related to cancer induction ${ }^{20}$.Thus, protein transcription and proteomic irradiation effects causing physiological changes and the pathological establishment had already been observed. All proteomicreviewedstudies ${ }^{10-20}$ were specific and targeted a physiological condition, and their findings cannot be generalized. However, those demonstrated the possibility of protein modulation induced by radiation in diverse human tissues. Our findings demonstrated similar blood protein modulation induced by radiation.

First of all, in the control group, each organ analyzed represented by a specific vascular site, showed a distinct albumin serum concentration itself, corresponding to a physiological vein identification. Indeed, there was a difference in albumin concentration in jugular in relation to other sites such as renal, hepatic, and pulmonary. However, there were no differences in albumin concentration among the hepatic, cava and renal sites. The brain metabolism changes the physiological jugular concentration of the albumin. This may be due to the water and plasma organ diffusions, which alter the protein concentration.

Second, in the irradiated group, there was a variation in the concentration of albumin in the vascular sites at the time of $72 \mathrm{~h}$ after irradiation. Such differences were in jugular and hepatic veins. Data showed that the whole body irradiation dose of $5 \mathrm{~Gy}$ could alter the expression of albumin in the blood due to brain and liver irradiation. This fact may contribute to the worsening of side effects since albumin is a major blood protein responsible for controlling blood osmolality and much of the transports of substances such as hormones and drugs.

Third, silver staining gel of jugular, renal, hepatic, vena cava, pulmonary of the three samples presented a standard coloration in which the albumin band from jugular sample took the strong silver staining color while other similar bands found larger areas with a central area at brighter color. Such brighter color in electrophoresis is found in bands of glycosylated proteins. Glycosylation is the process by which a sugar is covalently attached to a protein. Glycosylated proteins are difficult to stain with silver. The color standards found in the silver gel of jugular, renal, hepatic and vena cava samples may suggest that albumin is not glycosylated on the brain; while it may be in the bloodstream.

The increase of plasma proteins is associated with the increment of protein synthesis provided by the possible following facts: hypergamma globulinemy or paraproteinemy, hemoconcentration due to blood stasis during puncture, or reduction of the distributed volume due to dehydration. In turn, the lowering of the concentration of plasma proteins is associated with the decrease of protein synthesis provided by the reduction of distributed volume, by hyperhydration and by the increase of capillary permeability; or, by catabolism due to the rise of the excretion of proteins with the loss of catabolic state. Thus, the amounts of albumin in serum 
can fail due to the reduction of its synthesis in the liver and the loss in kidney and bowel.

Moreover, there are also many pathological processes that cause changes in plasma concentrations ${ }^{21}$.Hepatic and lung irradiation induces tissue inflammation, which may be the cause of albumin alterations. Our findings demonstrated that radiation induces the concentration changes of the albumin protein in serum. This phenomenon points out to alteration in gene metabolism in the liver, justified by a possible induction of proteomic damage from radiation.

\section{CONCLUSIONS}

The regional differential physiological concentration of albumin was identified on the jugular site. Besides, our findings from electrophoresis analysis suggest that the expression and the serum albumin concentrations may be modulated by radiation, representing an early effect of the whole body irradiation. This fact may be adjuvant on the increases in intensity and severity of the deleterious effects of the whole-body radiation, since the serum albumin, the most abundant protein in blood, is responsible for drugs and active substances transport and the control of systemic osmolality.

\section{ACKNOWLEDGEMENTS}

Authors are thankful to the Laboratory of Gamma Irradiation - LIG from Centro de Desenvolvimento de Tecnologia Nuclear - CDTN, who kindly pursued the irradiation. Authors are thankful to the Conselho National de Desenvolvimento da Ciência e Tecnologia (CNPq) by financial support, process 456719 / 2013-0 REBRAT-SUS, Fundação da Pesquisa do Estado de Minas Gerais - FAPEMIG, Universal Process FAPEMIG-18565 - FAPEMIG / EE / DENU / Ho-166, scholarships and DTI granted, and to Conselho de Apoio a Pós-graduação e Ensino Superior (CAPES) for a PhD scholarship granted.

\section{REFERENCES}

1. Hawk, J.L.M. and Norris, P.G. Abnormal Responses to Ultraviolet Radiation: Idiopathic. In: Fitzpatrick T.B. et al.,Dermatology in General Medicine. McGraw Hill.1993; 1661 1667.

2. Toledo J.M., Siqueira S.L., Falcao P.L., Campos T.P.R., Phenotypic behavior of dogs irradiated PBMC form based on flow cytometry, Journal of Biological regulators and Homeostatic Agents vo.27, .2. 309-317, 2013.

3. Solter M.P.; Walter E.H.; Hungerford L.L. et al. Haptoglobin and ceruloplasmin the determinants of inflammation in dogs. Am. J. Vet. Res., V.52, p.1738-1742, 1991.

4. Gruys E.; Obwolo, M. J.; Tousaint M.J.M. Diagnostic significance of the major acute phase proteins in veterinary clinical chemistry: a review. Vet. Bull., V.64, p.1009-1018, 1994.

5. Paula O., Silva C., Brandão K. M. A., Pinto P. V. M., Faria R.M. D., Clementino C. D., Lopes A. F., Multiple myeloma: clinical and laboratory characteristics in the diagnosis and prognostic study, Rev. Bras. Hematol. Hemoter. 2009; 31(2):63-68.

6. Oliveira R.P. and Silva V. A.; Lopes E.S., Malena Rose DELBONE, M.R.F. Electrophoresis of serum proteins: interpretation and clinical correlation of Minas Gerais, Medical Journal 2008; 18 (2): 116-122.

7. Calazans S.G., Daleck Fagliari J.J., Repetti C,F,, De Nardi B.A., Castro J.H.T., Fernandes S.C., Caesar S.C., Rodigheres M. Serum protein profile of healthy dogs with lymphoma and obtained by polyacrylamide (SDS-PAGE) gel. Arq. Bras. Med. Vet. Zootec., V.61, n.5, p.1044-1048, 2009. 
8. Gordon A.H. Electrophoresis of proteins in starch gels and polyacrilamide. New York: Elsevier, 1995, 213P.

9. Deim K. Synopsis of plasma proteins. In: Scientific Tables, 6th ed. Basel: DocumentaGeigy, 1962.

10. Anderson R.E. and Warner N.L. Radiosensitivity of T and B lymphocytes. III: Effect of radiation on immunoglobulin production by B cells.J Immunol. 1975 Jul;115(1):161-169.

11. Tapio S., Ionizing radiation effects on cells, organelles and tissues on proteome level.AdvExp Med Biol. 2013;990:37-48. doi: 10.1007/978-94-007-5896-4_2. Review.PMID:23378001. 2013.

12. Nylund R., Kuster N., Leszczynski D., Analysis of proteome response to the mobile phone radiation in two types of human primary endothelial cells. Proteome Sci. 2010 Oct 18;8:52. doi: 10.1186/1477-5956-8-52. PMID: 20955554. 2010.

13. Nylund R., Lemola E., Hakanen A., The lack of acute effect of low-to-moderate-dose ionising radiation on endothelial proteome. Int. J. Low Radiat. 9,127-137. 2013.

14. Yan Y., Xu H., Peng S., Zhao W., Wang B., Proteome analysis of ultraviolet-B- induced protein expression in vitro human dermal fibroblasts. Photodermatol Photoimmunol Photomed. 2010 Dec; 26(6):318-26. doi: 10.1111/j.1600-0781.2010.00556.x. 2010.

15. Yuasa M.S., Masutani C., Hiranoi A., Cohn M.A., Yamaizumi M., Nakatani Y., Hanoaka F., A human DNA polymerase eta complex containing Rad18, Rad6 and Rev1; proteomic analysis and targeting of the complex to the chromatin-bound fraction of cells undergoing replication fork arrest. Genes Cells. 2006 Jul;11(7):731-44. PMID: 1682419. 2006.

16. Karinen A., Heinara S., Nylund R., Leszczynski D., Mobile phone radiation might alter protein expression in human skin. BMC Genomics, 77-81. 2008.

17. Frangopolou A.F., Samara A., Antonelou M.H., Xanthopoulou A., Ppapadopoulou A., Vougas K., Koutsogiannopoulou E., Abastasiadou E., Stravopodis D.J., Tsangaris G.T., Margaritis L.H., Brain proteome response following whole body exposure of mice to mobile phone or wireless DECT base radiation.ElectromagnBiol Med. 2012 Dec;31(4):250-74. 2012,

18. Mattos D.M., Kimura E.T., Silva M.R.R., Egami M.I., Segreto R.A., Segreto H.R.C., Ativação da Proteína TGF $\beta 1$ latente em pulmão irradiado in vivo. Revista Associação Médica Brasileira, São Paulo, SP. 2002.

19. Falcao PL, Cuperschmid E.M.; Trindade B.M.; Campos T.P.R., Transforming growth factor-b and matrix metalloproteinase secretion in cell culture from ex vivo PBMC after exposure to UV radiation, Journal of Biological regulators and Homeostatic Agents, Vol. 28th, n.2, 333-340, 2014.

20. Gabay Y. C., Kushner I., Acute-phase proteins and other systemic responses to inflammation. N. Engl. J. Med., V.340, p.448-454, 1999.

21. Murata H.; Shimada N.; Yoshimoka M., Current research on acute phase proteins in veterinary diagnosis: an overview. Vet. J., v.168, p.28-40 2004. 